\title{
Triphala: a miracle herb in the field of dentistry
}

\begin{abstract}
Ayurveda aim to ensure a healthy mind and healthy body by not only providing cure of illness, but also elaborating the means for maintaining of health, Ayurveda attempts in correcting the imbalances and derangements of bodily humours and to re-establish equilibrium conditions by the application of all spiritual and material resources obtainable to man. Inspite of vast development of modern medical science, satisfactory treatment of "oral diseases" by newer drugs is into achieved, the chemical compounds has exposed the patients to its diverse ill effects, consequently, there is curiosity to find out effective remedy of any disease by harmless herbal drugs. Triphala is one of the well known Indian ayurvedic herb consisting of dried and powdered fruits of three medicinal plants namely Terminalia Bellerica Roxb (Bibhitaki), Terminalia chebula Retz (Haritaki) and Embellica officinalis Gaertn (Amalaki).
\end{abstract}

Keywords: triphala, periodontitis
Volume 9 Issue I - 2018

\section{Sruthi K Nair, Shivaprasad BM}

Department of Periodontology, Rajarajeswari Dental College and Hospital, India

Correspondence: Sruthi K Nair, Post graduate student, Department of Periodontology, Rajarajeswari Dental College and Hospital, \# 4 ramoholli cross, Kumbalgodu, Bangalore, India, Tel +918861795247, Email sruthianoop9900@gmail.com

Received: May II, 2017 | Published: January 09, 2018

\section{Introduction}

Triphala is one of the well recognized Indian ayurvedic herbal formulation consisting of dried and powdered fruits of three medicinal plants namely Terminalia Bellerica Roxb (Bibhitaki), Terminalia chebula Retz (Haritaki) and Embellica officinalis Gaertn (Amalaki). ${ }^{1}$ There is a folk saying in India which says, "No Mother? Do not worry so long as you have Triphala". This is insinuation to the belief that Triphala cares for internal organs, just as a mother takes care of her children, ${ }^{2}$ and among laxative herbs, triphala is the 'safest and most strengthening. Triphala has been described in the ancient ayurvedic text as a Tridoshic rasayana, a therapeutic agent with balancing and rejuvenating effects on the three humours or constitutional elements in ayurvedic vata, pitta and kapha. Terminalia chebula Retz and Terminalia Bellerica Roxb have a warm energy, while Embellica officinalis is cool in nature. Triphala being a combination of all three, is balanced, making it useful as an internal cleansing, detoxifying formula. It is regarded as an essential rasayana and good purgative in ayurvedic medicine. Recipe for this traditional herbal supplement is described in the traditional Indian texts, the Charaka and Susruta Samhita. $^{2}$

\section{Triphala in oral and periodontal diseases}

\section{Anti-caries activity}

Despite several anti plaque agents available in the market, the search for an effective agent still continues. Several unwanted side effects associated with these agents stimulated the search for alternate agents. Plants or plant products used in folk dental practices or prescribed in unani, homeopathic, or ayurvedic remedies are now getting hold of attention in view of their acclaimed medicinal properties. Terminalia chebula is valuable in preventing and treating several diseases of the mouth such as dental caries, spongy and bleeding gums, gingivitis, and Stomatitis. The extract could successfully avert plaque formation on the surface of the tooth, as it repressed the sucrose induced adherence and the glucan induced aggregation, the two processes which foster the colonization of the organism on the surface of the tooth. Thus, the extract of T. chebula may be an effective agent in the treatment of carious teeth, owing to its ability to inhibit the growth and accumulation of S. mutans on the surface of the tooth. This would prevent the accumulation of acids on the surface of the tooth, and thus the further demineralization and the breakdown of the tooth enamel. ${ }^{3}$

\section{Triphala as a root canal irrigant}

Primary endodontic infections are caused by oral microorganisms, which are usually opportunistic pathogens that may invade a root canal containing necrotic tissue and establish an infectious process. The number of facultative anaerobic bacteria increases when the root canal remains infected for long periods. Enterococcus faecalis, a facultative anaerobic gram positive coccus, is the most frequent Enterococcus sp. cultured from non healing endodontic cases. Sodium hypochlorite $(\mathrm{NaOCl})$ is an efficient irrigant used in eliminating E. faecalis biofilms in vitro, but its main disadvantages are its unpleasant taste, high toxicity, and its inability to remove the smear layer. Triphala has revealed a remarkable antibacterial activity against three and six week biofilms. The use of herbal alternatives as a root canal irrigant might prove to be advantageous considering the several undesirable characteristics of $\mathrm{NaOCl}$

\section{Anti-collagenase activity of Triphala}

Matrix metalloproteinases play an unique and important role in periodontal destruction, and this information guide to a new concept linking the chemotherapeutic inhibition of these enzymes. Doxycycline is most potent tetracycline for collagenase/gelatinase inhibition. However, long-term tetracycline therapy has certain disadvantages. Use of herbal product extract in treating periodontal disease does not produce side effects of tetracycline compounds as well as other synthetic drugs. Triphala has strong inhibitory activity against PMN type collagenase, especially MMP 9 at a $1500 \mu \mathrm{g} / \mathrm{ml}$ concentration, which is well within the safety profile of toxicological studies. ${ }^{4}$

\section{Anti-microbial and anti-oxidant effect of Triphala}

Antimicrobial and antioxidant effect of Triphala has been proven in vitro as it has been shown to inhibit Streptococcus mutans at 
concentrations as low as $50 \mu \mathrm{g} / \mathrm{ml}$. This anti plaque result almost certainly may be due to the tannic acid in Triphala, which is adsorbed well to the groups on the surface of the bacterial cells, which result in protein denaturation and ultimately to bacterial cell death. The strong antioxidant action of Triphala may be attributed to T. belerica, which is the most energetic antioxidant followed by E. officinalis and $\mathrm{T}$. chebula. The major ingredients of $\mathrm{T}$. Belerica are ellagic and Gallic acid; E. officinalis has several Gallic acid derivatives including epigallocatechingallate and in T. chebula, Gallic acid is the major ingredient. The presence of these active ingredients of phenolic nature may be responsible to scavenge the free radicals. ${ }^{5}$

\section{Triphala as mouth rinse}

Ayurvedic drugs have been used since ancient times. Oral rinses made from these are used in periodontal therapy. Triphala has a wide spectrum of activity. According to the Sushruta Samhita, the Triphala herb can be used as a gargling agent in dental diseases. $0.6 \%$ Triphala mouthwash has shown to have significant anti caries activity, which is comparable to that of chlorhexidine without possessing disadvantages as staining of teeth and cost effective although there was no evidence of remineralisation of tooth structure. ${ }^{6}$ Triphala mouth rinse in combination with scaling and root planing showed significant decrease in the plaque, gingival, and oral hygiene indices without any evidence of staining of teeth at seven, 30 , and 45 days, which was comparable to reduction obtained by chlorhexidine mouth rinse in combination with scaling and root planing.?

Triphala mouthwash twice daily combined with metronidazole $400 \mathrm{mg}$ thrice daily when compared with $0.2 \%$ chlorhexidine with metronidazole $400 \mathrm{mg}$ thrice daily and Triphala mouthwash with oral powder of Triphala in a one month study showed significant improvement in clinical indices in terms of reduction in tooth mobility, pocket depth, bleeding gums, sensitivity to hot and cold, and calculus formation with minimal recurrence in all the clinical parameters. ${ }^{8}$ $0.6 \%$ Triphala mouthwash and $0.1 \%$ CHX exhibited an alike trend to prevent formation of plaque with progressive reduction in the plaque scores from the baseline till the end of 9 months. Both groups also showed similar outcomes on gingival health and inhibitory effects on microbial counts, except Lactobacillus count where Triphala showed better results than Chlorhexidine. ${ }^{9} 6 \%$ Triphala when used twice a day brought down the oral streptococci count by $17 \%$ and $44 \%$ compared to $0.2 \%$ chlorhexidine group which showed $16 \%$ and $45 \%$ reduction at the end of $48 \mathrm{~h}$ and 7 days respectively suggestive of an anti-oralstreptococci efficacy of Triphala comparable to that of chlorhexidine. ${ }^{10}$

\section{Funding details}

None.

\section{Acknowledgments}

None.

\section{Conflicts of interest}

The authors declare that there are no conflicts of interest.

\section{References}

1. Prabhakar J, Senthilkumar M, Priya MS, et al. Evaluation of antimicrobial efficacy of herbal alternatives (Triphala and green tea polyphenols), MTAD, and 5\% sodium hypochlorite against Enterococcus faecalis biofilm formed on tooth substrate: An in vitro study. $J$ Endod. 2010;36(1):83-86.

2. Bali Chouhan. Triphala: a comprehensive Ayurvedic Review. Int $J$ Res Ayurveda Pharm. 20008;4(4):612-617.

3. Jagtap AG, Karkera SG. Potential of the aqueous extract of Terminalia chebula as an anticaries agent. J Ethnopharmacol. 1999;68(1-3):299-306.

4. Abraham S, Kumar MS, Sehgal PK, et al. Evaluation of the inhibitory effect of Triphala on PMN-type Matrix Metalloproteinase (MMP-9). J Periodontol. 2005;76(4):497-502.

5. Jagdish L, Anand Kumar VK, Kaviyarasan V. Effect of Triphala on dental biofilm. Indian J Sci Technol. 2009;2(1):30-33.

6. Tandon S, Gupta K, Rao S, et al. Effect of Triphala mouthwash on caries status. Int J Ayurveda Res. 2010;1(2):93-99.

7. Desai A, M Anil, Debnath S. A clinical trial to evaluate the effects of Triphala as a mouthwash in comparison with chlorhexidine in chronic generalized periodontitis patient. Indian J Dent Adv. 2010;2:243-247.

8. Maurya DK, Mittal N, Sharma KR, et al. Role of triphala in the management of Periodontal disease. Anc Sci Life. 1997;17(2):120-127.

9. Bajaj N, Tandon S. The effect of Triphala and Chlorhexidine mouthwash on dental plaque, gingival inflammation, and microbial growth. Int $J$ Ayurveda Res. 2011;2(1):29-36.

10. Srinagesh J, Krishnappa P, Somanna SN, Antibacterial efficacy of triphala against oral streptococci: An in vivo study. Indian J Dent Res. 2012;23(5):696 